\title{
Micronychia of the Index Finger
}

\author{
Anil Harishchandra Patki, MD; Paras Choudhary, MD
}

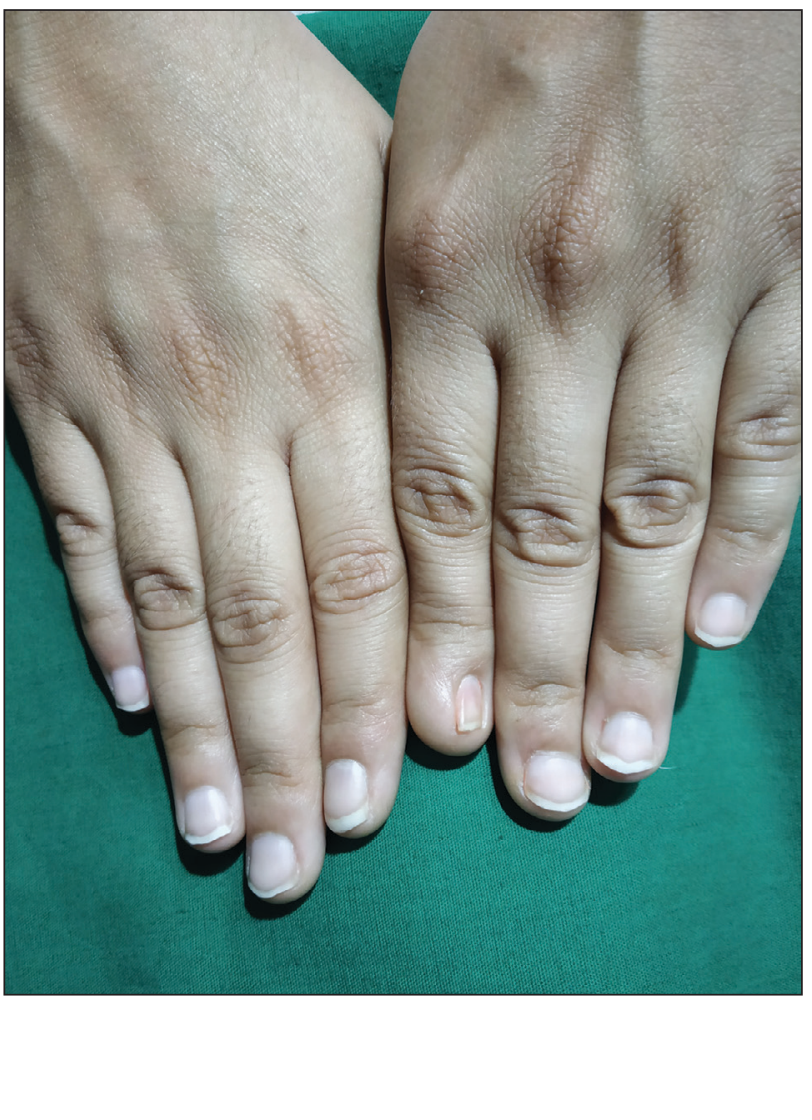

A 21-year-old Indian woman who was initially seeking dermatology consultation for acne also was noted to have micronychia of the nail of the left index finger. The affected nail was narrow and half as broad as the unaffected normal nail on the right index finger. The patient confirmed that this finding had been present since birth; she faced no cosmetic disability and had not sought medical care for diagnosis or treatment. There was no history of trauma, complications during pregnancy, family history of micronychia or similar eruptions, or any other inciting event. The teeth, hair, and skin as well as the patient's height, weight, and physical and mental development were normal. Systemic examination revealed no abnormalities. Radiography of the hands did not reveal any apparent bony abnormalities.

\section{WHAT'S YOUR DIAGNOSIS?}

a. congenital onychodysplasia of the index finger

b. DOOR syndrome

c. hidrotic ectodermal dysplasia

d. nail-patella syndrome

e. Poland syndrome 


\section{THE DIAGNOSIS:}

\section{Congenital Onychodysplasia of the Index Finger}

$\longrightarrow$ ongenital onychodysplasia of the index finger (COIF), or Iso-Kikuchi syndrome, is a rare disorder characterized by malformation of one or both nails of the index fingers. The various anomalies described are anonychia, micronychia, polyonychia, malalignment, or hemi-onychogryphosis. It may be associated with abnormalities of the underlying phalangeal bone, the most masked being bifurcation of the terminal phalange. ${ }^{1}$ Initially thought to be nonhereditary and nonfamilial, ${ }^{2}$ it is now known that COIF can be inherited in an autosomal-dominant fashion. ${ }^{3}$ Millman and Strier $^{3}$ described a family of 9 patients with COIF. It rarely is described outside of Japan. Padmavathy et $\mathrm{al}^{4}$ described a case in an Indian patient with COIF that was associated with the absence of a ring finger in addition to anomalies of the metacarpal bones.

Congenital onychodysplasia of the index finger has a broad spectrum regarding its etiology and clinical features. ${ }^{5}$ The pathogenesis of COIF still is poorly understood. Deficient circulation in digital arteries is thought to be a putative mechanism for developing a deformed nail. The nail is affected on the radial side of the index finger, likely because of the smaller caliber of the artery on that side. ${ }^{5}$ Hereditary as well as nonhereditary sporadic cases have been reported. In addition to the various fingernail anomalies, skeletal abnormalities also have been reported. Baran and Stroud ${ }^{6}$ have reported deformed lunulae as a manifestation of COIF.

The differential diagnosis of COIF includes hidrotic ectodermal dysplasia, nail-patella syndrome, Poland syndrome, and DOOR syndrome. Hidrotic ectodermal dysplasia exhibits onychodystrophy, generalized hypotrichosis, palmoplantar keratoderma, and dental anomalies. ${ }^{7}$ Nail-patella syndrome presents with hypoplasia of the fingernails and toenails, triangular nail lunulae, absent or hypoplastic patellae, and elbow and iliac horn dysplasia. Poland syndrome is distinguished from COIF by the congenital absence of the pectoralis major muscle on the ipsilateral side of the involved digits. The DOOR syndrome tetrad is comprised of deafness, onychodystrophy, osteodystrophy, and mental retardation. ${ }^{8}$ Unlike these conditions, COIF does not involve systems other than the nails and phalanges.

Treatment of this condition is mainly conservative, as patients typically do not have symptoms. ${ }^{9}$ Surgical interventions can be considered for cosmetic concerns. Knowledge of this congenital entity and its clinical findings is essential to prevent unnecessary procedures and workup.

\section{REFERENCES}

1. De Berker AR, Baran R. Science of the nail apparatus. Diseases of the Nails and Their Management. In: Baran R, De Berker AR, Holzberg M, et al, eds. 4th ed. Willey-Blackwell; 2012:1-50.

2. Kikuchi I, Horikawa S, Amano F. Congenital onychodysplasia of the index fingers. Arch Dermatol. 1974;110:743-746.

3. Millman AJ, Strier RP. Congenital onychodysplasia of the index fingers: report of a family. J Am Acad Dermatol. 1982;7:57-65.

4. Padmavathy L, Rao L, Ethirajan N, et al. Iso-Kikuchi syndrome with absence of ring fingers and metacarpal bone abnormality. Indian J Dermatol Venereol Leprol. 2008;74:513.

5. Hadj-Rabia S, Juhlin L, Baran R. Hereditary and congenital nail disorders. In: Baran R, De Berker AR, Holzberg M, et al, eds. Diseases of the Nails and Their Management. 4th ed. Wiley-Blackwell; 2012:485-490.

6. Baran R, Stroud JD. Congenital onychodysplasia of the index fingers: Iso and Kikuchi syndrome. Arch Dermatol. 1984;120:243-244.

7. Valerio E, Favot F, Mattei I, et al. Congenital isolated Iso-Kikuchi syndrome in a newborn. Clin Case Rep. 2015;3:866.

8. Danarti R, Rahmayani S, Wirohadidjojo YW, et al. Deafness, onychodystrophy, osteodystrophy, mental retardation, and seizures (DOORS) syndrome: a new case report from Indonesia and review of the literature. Eur J Dermatol. 2020;30:404-407.

9. Milani-Nejad N, Mosser-Goldfarb J. Congenital onychodysplasia of index fingers: Iso-Kikuchi syndrome. J Pediatr. 2020;218:254. 